\title{
SPOR BILIMLERINDE ÖĞRENME VE ÖĞRENME STILLERi
}

\author{
Dr. Üstün TÜRKER
}




\section{(C) Copyright 2021}

Bu kitabın, basım, yayın ve satış hakları Akademisyen Kitabevi A.Ş.'ne aittir. Anılan kuruluşun izni alınmadan kitabin tümü ya da bölümleri mekanik, elektronik, fotokopi, manyetik kağıt ve/veya başka yöntemlerle çoğaltılamaz, basılamaz, dağıtılamaz. Tablo, şekil ve grafikler izin alınmadan, ticari amaçh kullanılamaz. Bu kitap T.C. Kültür Bakanlı̆̆ bandrolü ile satılmaktadır.

Bu kitapta yer alan fikirler ve düşünceler yazara ait olup, hiçbir kurum veya kuruluşun görüşünü yansıtmamaktadır. Bu kitap "Spor Bilimleri Fakültesi Öğrencilerinin Öğrenme Stili Modelleri ve Tercihlerinin Karşılaştırılması"adlı yüksek lisans tezinden üretilmiştir.

ISBN

978-625-8037-01-2

Kitap Adı

Spor Bilimlerinde Öğrenme ve Öğrenme Stilleri

Editör

Doç. Dr. Özgür BOSTANCI

ORCID iD: 0000-0002-7952-1014

Yazar

Üstün TÜRKER

ORCID iD: 0000-0003-0604-8577

Yayın Koordinatörü
Yasin DİLMEN

Sayfa ve Kapak Tasarımı

Akademisyen Dizgi Ünitesi

Yayıncı Sertifika No

47518

Baskı ve Cilt

Vadi Matbaacilık

Bisac Code

SPO000000

DOI

10.37609/akya.746

GENEL DAĞITIM

Akademisyen Kitabevi A.Ş.

Halk Sokak 5 / A

Yenişehir / Ankara

Tel: o312 4311633

siparis@akademisyen.com 


\section{ÖNSÖZ}

Başta kıymetli ailem, kısa bir süre önce dünyadaki 1’nci yaşını tamamlayan yeğenim Elif Mısra ve Ondokuz Mayıs Üniversitesi’nde tamamlamış olduğum Yüksek Lisans ve Doktora eğitimlerim süresince lisansüstü danışmanlığımı yürüten hocam, değerli büyüğüm Doç. Dr. Özgür BOSTANCI olmak üzere, değerli görüşleri ile araştırmaya katkılarını sunan hocalarıma, OMÜ Yaşar Doğu Spor Bilimleri Fakültesi’nin eski dekanlarından merhum Prof. Dr. M. Yalçın TAŞMEKTEPLİGíLe, eğitim hayatım boyunca üzerimde emeği bulunan tüm öğretmenlerime ve "Spor Bilimlerinde Öğrenme ve Öğrenme Stilleri” başlıklı bu kitabın tasarımında, dizgisinde, baskısında emeği geçen ve sizlere kadar ulaşmasını sağlayan Akademisyen Kitabevi ve çalışanlarına teşekkürü bir borç bilir, saygı ve sevgilerimi sunarım.

Dr. Üstün TÜRKER 
- 
"Kıymetli dostum, merhum Samet ÇAKMAK'a ithafen..." 
- 


\section{IÇiNDEKILER}

\section{Bölüm 1}

Giriş ............................................................................................................... 1

\section{Bölüm 2}

Genel Bilgiler.......................................................................................... 3

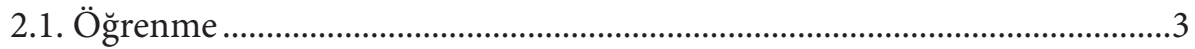

2.2. Öğrenme Kuramları .................................................................................

2.2.1. Davranış̧̧ı Öğrenme Kuram1 ..................................................................

2.2.2. Bilişsel Öğrenme Kuram1......................................................................6

2.2.3. Bilişsel Ağırlıklı Davranışçı Öğrenme Kuramı .........................................7

2.2.4. Duyuşsal Öğrenme Kuramı...................................................................

2.2.5. Yapılandırmacı (Oluşturmacılık) Öğrenme Kuramı.............................8

2.2.6. Nörofizyolojik Öğrenme Kuramı.......................................................9

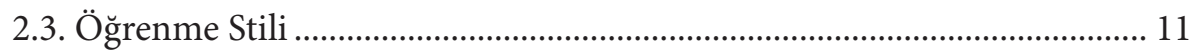

2.4. Eğitim - Öğretimde Öğrenme Stilinin Önemi ............................................. 13

2.5. Öğrenme Stillerinin Öğretme-Öğrenme Sürecindeki Rolü....................... 14

2.6. Öğrenmede Bireysel Farklılıklar................................................................ 15

2.7. Birey ile Öğrenme Stili Arasındaki İlişki.................................................... 15

2.8. Öğrenme Stili Sinıflamaları....................................................................... 16

2.9. Öğrenme Stili Modelleri ............................................................................ 18

2.9.1. Jung Öğrenme Stili Modeli................................................................ 18

2.9.2. Lawrance Öğrenme Stili Modeli .......................................................... 20

2.9.3. Merrill Sosyal Tipleri............................................................................ 21

2.9.4. Hunt Tipleri ................................................................................... 21

2.9.5. Reinert Öğrenme Stili Modeli ......................................................... 22

2.9.6. Carbo Öğrenme Stili Modeli ............................................................... 23

2.9.7. Myers - Briggs Öğrenme Stili Modeli .................................................. 24

2.9.8. Bernice McCarthy Öğrenme Stili Modeli (4MAT Sistemi) ............. 25

2.9.9. Honey ve Mumford Öğrenme Stili Modeli ......................................... 27

2.9.10. Silver - Hanson Öğrenme Stili Modeli ............................................. 28

2.9.11. Witkin'in Alan Bağımlı - Alan Bağımsız Biliş Stili Modeli............ 28 
viii | Spor Bilimlerinde Öğrenme ve Öğrenme Stilleri

2.9.12. Gregorc Öğrenme Stili Modeli........................................................... 29

2.9.13. Butler Öğrenme Stili Modeli .............................................................. 30

2.9.14. Grasha - Riechmann Öğrenme Stili Modeli..................................... 31

2.9.15. Canfield Öğrenme Stili Modeli....................................................... 32

2.9.16. Dunn ve Dunn Öğrenme Stili Modeli ............................................... 33

2.9.17. Kolb Öğrenme Stili Modeli ............................................................ 35

2.9.18. Vark Öğrenme Stili Modeli............................................................... 38

\section{Bölüm 3}

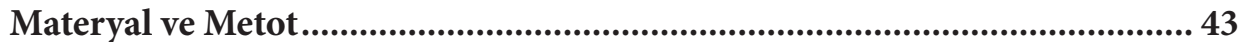

3.1 Araştırmanın Modeli ...................................................................................... 43

3.2. Araştırmanın Evreni ve Örneklemi................................................................. 43

3.3. Veri Toplama Araçları.................................................................................. 44

3.3.1. Kişisel Bilgi Formu ............................................................................... 44

3.3.2. Kolb Öğrenme Stili Envanteri - Versiyon III (KÖSE-III) ................. 44

3.3.2.1. KÖSE-III Güvenirlik ve Geçerlik Katsayıları ............................. 47

3.3.3. Vark Öğrenme Stili Envanteri ........................................................... 48

3.3.3.1. VARK Güvenirlik ve Geçerlik Katsayıları.................................... 48

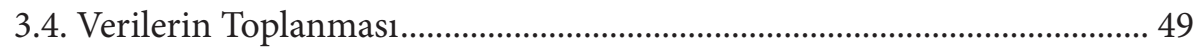

3.5. Verilerin İstatistiksel Analizi ve Yorumlanması .......................................... 49

\section{Bölüm 4}

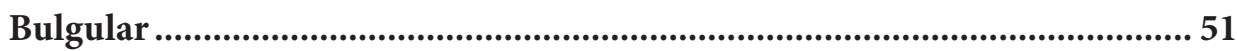

\section{Bölüm 5}

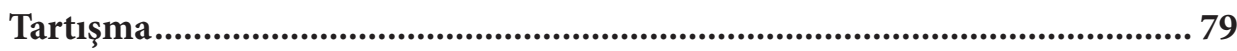

\section{Bölüm 6}

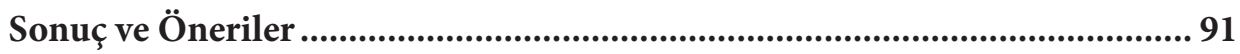

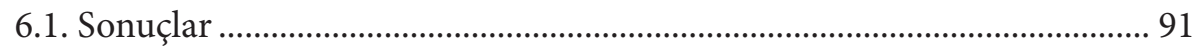

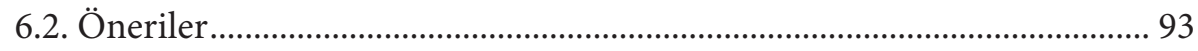

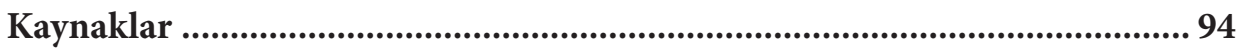




\section{SIMGELER VE KISALTMALAR}

\begin{tabular}{|c|c|}
\hline A & : Aural (İşitsel) \\
\hline AEB & : Antrenörlük Eğitimi Bölümü \\
\hline AT & : Ayrıştıran Tip \\
\hline$A \ddot{U}$ & : Ardahan Üniversitesi \\
\hline AY & : Aktif Yaşantı \\
\hline BSÖ & : Beden Eğitimi ve Spor Öğretmenliği Bölümü \\
\hline BESYO & : Beden Eğitimi ve Spor Yüksekokulu \\
\hline BÖTE & : Bilgisayar ve Öğretim Teknolojileri Eğitimi Bölümü \\
\hline Çı̇Ö & : Çift Öğrenme \\
\hline ÇÖ & : Çoklu Öğrenme \\
\hline DHK & : Diş Hekimliği Fakültesi \\
\hline DT & : Değiştiren Tip \\
\hline FÜ & : Firat Üniversitesi \\
\hline FBÖB & : Fen Bilgisi Öğretmenliği Bölümü \\
\hline HB & : Hemşirelik Bölümü \\
\hline İ̈BF & : İktisadi ve İdari Bilimler Fakültesi \\
\hline K & : Kinesthetic (Kinestetik) \\
\hline KÖSE-III & : Kolb Öğrenme Stili Envanteri 3. Versiyon \\
\hline KPSS & : Kamu Personeli Seçme Sınavı \\
\hline KTÜ & : Karadeniz Teknik Üniversitesi \\
\hline LYS & : Lisans Yerleştirme Sınavı \\
\hline MM & : Multi-Modal (Çok Yönlü) \\
\hline MÖB & : Müzik Öğretmenliği Bölümü \\
\hline MÜF & : Mühendislik Fakültesi \\
\hline OMÜ & : Ondokuz Mayıs Üniversitesi \\
\hline ÖT & : Özümseyen Tip \\
\hline
\end{tabular}


x | Spor Bilimlerinde Öğrenme ve Öğrenme Stilleri

$\begin{array}{ll}\text { R/W } & \text { : Reading (Okuyan), Writing (Yazan) } \\ \text { RB } & \text { : Rekreasyon Bölümü } \\ \text { RIÖB } & \text { : Resim-İ̧̧̈̈̆ğretmenliği Bölümü } \\ \text { SBF } & \text { : Spor Bilimleri Fakültesi } \\ \text { SBÖB } & \text { : Sosyal Bilgiler Öğretmenliği Bölümü } \\ \text { SD } & \text { : Somut Deneyim } \\ \text { SK } & \text { : Soyut Kavramsallaştırma } \\ \text { SÖB } & \text { : Sınıf Öğretmenliği Bölümü } \\ \text { SYB } & \text { :Spor Yöneticiliği Bölümü } \\ \text { TF } & \text { : Tip Fakültesi } \\ \text { TEF } & \text { : Teknik Eğitim Fakültesi } \\ \text { TÖ } & \text { : Tekli Öğrenme } \\ \text { TÖB } & \text { : Türkçe Öğretmenliği Bölümü } \\ \text { ÜÖ } & \text { : Üçlü Öğrenme } \\ \text { V } & \text { : Visual (Görsel) } \\ \text { VARK } & \text { : Vark Öğrenme Stili Envanteri } \\ \text { YG } & \text { : Yansıtıcı Gözlem } \\ \text { YGS } & \text { : Yükseköğretime Geçiş Sınavı } \\ \text { YT } & \text { : Yerleştiren Tip } \\ \text { YDYO } & \text { : Yabancı Diller Yüksekokulu }\end{array}$




\section{4 | Spor Bilimlerinde Öğrenme ve Öğrenme Stilleri}

farkındalık yaratılmalıdır. Böylelikle lisans eğitimini başarılı bir şekilde tamamlayan SBF ve BESYO öğrencilerinin, kendi mesleklerini icra etmeye başladığı dönemde sorumlusu olduğu öğrenme ve öğretme ortamlarını maksimum seviyede verimli kullanabileceklerdir.

- Öğrencilerin kendi yeteneklerini, öğrenme biçemlerini, öğrenme stilini veya stratejilerini tanılayabilmeleri için spor bilimleri alanında öğretime devam etmekte olan akademik birimlere Rehberlik ve Psikolojik Danışma birimleri kurulmalı ve mevcut olanların daha işlevsel şekilde faaliyetlerini sürdürmeleri sağlanmalıdır.

- Araştırma sonuçlarımız R/W öğrenme biçemine, sınıf seviyesi ve yaş grupları arttıkça tercihin düştüğünü göstermiştir. Bu bulgular doğrultusunda araştırmacılara, farklı yaş grupları ve öğrenim düzeyleri üzerinde yeni araştırmalar yapılmasinı önermekteyiz.

- SBF ve BESYO öğrencilerinin 1. sınıf düzeyindeki R/W öğrenme biçemine yönelik tercihlerinin, sınıf düzeyinin artmasıyla birlikte düzenli bir düşüş göstermesinin önlenebilmesi için, öğrenciler mezuniyetine kadar ki süreçte öğretim elamanları tarafından araştırma yapmaya yönlendirilmeli, akademik gelişimleri desteklenmeli ve özendirilmelidir. Ayrıca teorik derslere olan ilgilerinin yüksek tutulması sağlanmalıdır.

\section{KAYNAKLAR}

Açıkgöz K.Ü. Etkili Öğrenme ve Öğretme. İzmir, 1996; 53.

Adatepe E. Ortaokul 7. ve 8. Sınıf Öğrencilerinin Öğrenme Stilleri ile Çalışma Alışkanlıkları ve Akademik Başarıları Arasındaki İlişkinin İncelenmesi. Fatih Üniversitesi Sosyal Bilimler Enstitüsü, İstanbul, Yüksek Lisans Tezi, 2014; 37.

Ahmed J., Shah K., Shenoy N., Srikant N. How Different Students and Their Learning Styles ? International Journal of Research in Medical Sciences, DOI: 10.5455/2320.6012.ijrms20130808, 2013; 212-215.

AIKhasawneh E. Using VARK to assess changes in learning preferences of nursing students at a public university in Jordan ; Implications for teaching. Nurse Education Today, Elsevier, 2013; 1546-1549.

Alemdağ C., Bozkara A.B., Alemdağ S., Kalkavan A. Eğitim Kademesi ve Akademik Başarı Açısından Sporcu Öğrencilerin Öğrenme Stilleri. International Journal of Science Culture and Sport, DOI: 10.14486/lnJSCS543, 2016;146-155.

Alemdağ C. ve Öncü E. Kolb Öğrenme Stili Modeline Göre Beden Eğitimi Öğretmen Adayları. Karadeniz Teknik Üniversitesi Alan Eğitimi Araştırmaları Dergisi (ALEG) Cilt:1, Sayı:1, 2015; 1-12.

Altun F. Müzik Öğretmenliği Adaylarının Öğrenme Stilleri, Problem Çözme Becerileri ve Alan Başarı Puanları Arasındaki İlişkiler. İnönü Üniversitesi Eğitim Bilimleri Enstitüsü, Malatya, Yüksek Lisans Tezi, 2015.

Appleton K. Analysis and Description of Students Learning During Science Classes Using A Constructivist-Based Model. Journal of Research in Science Teaching, Cilt:34, Sayı: 3, 1997; 303318. 
Ateş A. ve Altun E. Bilgisayar ve Öğretim Teknolojileri Eğitimi Öğrencilerinin Öğrenme Biçemleri ve Öğrenme Tercihleri. Eurasian Journal of Educational Research, 2008; 1-16.

Babadoğan C. Öğretim Stili Odaklı Ders Tasarımı Geliştirme. Milli Eğitim, 147: Temmuz, Ağustos, Eylül, 2000.

Babadoğan C. Öğrenme Stilleri ve Stratejileri Arasındaki İlişki. I. Eğitim Kongresi, Adana, Çukurova Üniversitesi, Cilt:3 1995; 1058.

Babadoğan C. "Stil Temelli Öğretim ve Ders Tasarımı", Öğretim İlke ve Yöntemleri. Ankara, Maya Akademi Yayın Dağıtım, 2008; 340.

Bacanlı H. Gelişim ve Öğrenme. 6. Baskı, Ankara, Nobel Yayın Dağıtım, 2002.

Bahar H.H., Polat R., Özbaş M. Resim, Müzik ve Beden Eğitimi Öğretmenliği Adaylarının Öğrenme Stilleri. Erzincan Üniversitesi Eğitim Fakültesi Dergisi, Cilt-Sayı: 18-1, DOI: $\quad 10.17556 /$ jef.38844, 2016; 409-424.

Baykan Z. ve Naçar M. Learning Styles of First-Year Medical Students Attending Erciyes University in Kayseri, Turkey. DOI: 10.1152/avdan.00043.2006, 2007; 158-160.

Becther C. ve Esichaikul V. Using Kolb’s Learning Style Inventory for E-Learning Ersonalization. IADIS International Conference on Cognition and Exploratory Learning in Digital Age, 2008.

Bektaş F. Determining Learning Styles of the Professional Mountainers. Academic Journals, DOI: 10.5897/ERR2013.1116, 2013; 212-217.

Biçer M. İlköğretim 6.,7.,8. Sınıf Öğrencilerinin Sınıf Düzeyleri, Cinsiyetleri, Akademik Başarıları ve Ders Grupları ile Öğrenme Stilleri Arasındaki İlişki. Yıldız Teknik Üniversitesi Sosyal Bilimler Enstitüsü, İstanbul, Yüksek Lisans Tezi, 2010; 10-57.

Biggs J. Enhancing learning A Matter of Style or Approach. Mahwah: Lawarance Erlbaum Associates, 2001; 73-102.

Bolat N.K. İlköğretim 6. ve 7. Sınıf Fen ve Teknoloji Dersi Öğrencilerinin Öğrenme Stillerine Göre Motivasyon ve Başarı Düzeyleri. Eskişehir Osmangazi Üniversitesi Fen Bilimleri Enstitüsü, Eskişehir, Yüksek Lisans Tezi, 2007; 54.

Boydak A. Öğrenme Stilleri. 1. Baskı, İstanbul, Beyaz Yayınları. 2001; 4-8.

Bozkurt O. İlköğretim 6. Sınıf Fen Bilgisi Dersinin Dunn ve Dunn Öğrenme Stili Modeli Kullanılarak Öğretilmesinin Öğrencilerin Akademik Başarı, Tutum ve Bilimsel Süreç Becerileri Üzerine Etkisi. Gazi Üniversitesi Eğitim Bilimleri Enstitüsü, Ankara, Doktora Tezi, 2005; 51-70.

Braakhuis A., Williams T., Fusco E., Hueglin S., Popple A. A Comparison Between L e a r ning Style Preferences, Gender, Sport and Achievement in Elite Team Sport Athletes. SPORTS, DOI: $10.3390 /$ sports3040325, 2015; 325-334.

Breckler J., Joun D., Ngo H. Learning Styles of Physiology Students Interested in the Health Professions. DOI: 10.1152/avdan.90118.2008, 2009; 30-36.

Butler K.A. Learning and Teaching Style. In Theory and Practice. Colombia, The Learner's Dimension, 1987.

Büyükkaragöz S. ve Çivi S. Genel Öğretim Metotları. 7. Baskı, İstanbul, Öz Eğitim Yayınları, 1997.

Büyüköztürk Ş. Sosyal Bilimler İçin Veri Analizi Kitabı. 22. Baskı, Ankara, Pegem Akademi. 2016; 32.

Caine R.N. ve Caine G. Understanding A Brain Based Approach to Learning and teaching. Educational Leadership, October, 1990; 32.

Carbo M. Deprogramming Reading Failure : Giving Unequal learners an Equal Chance. PHI delta Kappan The journal for education. November, 1987.

Çağlayan H.S. ve Taşğın Ö. Beden Eğitimi ve Spor Yüksekokulu Sınavına Başvuran Aday Öğrencilerin Öğrenme Biçemlerinin İncelenmesi, 2008.

Çelik F. ve Şahin H. Beden Eğitimi ve Spor Öğretmenliği Adaylarının Cinsiyet ve Öğrenim Gördükleri Sınıf Düzeyleri Bakımından Öğrenme Stillerinin İncelenmesi (MAKÜ Örneği). Buca Eğitim Fakültesi Dergisi, Sayı: 31, 2001; 23-38. 


\section{6 | Spor Bilimlerinde Öğrenme ve Öğrenme Stilleri}

Çetin M.Ç. Evaluation of the Correlation Between Learning Styles and CriticalThinking Dispositions of the Students of School of Physical Education and Sport. Academic Journals, DOI: 10.5897/.ERR2014.1813, 2014; 680-690.

De Cecco J.P. The Psychology Learning and Instruction : Educational Psyhology. New Jersey : Prentice-Hall, 1968.

Deniz J. Müzik Öğretmenliği Adaylarının Öğrenme Stilleri. 2. International Conference on New Trends in Education and Their Implications, 27-29 April, Antalya, Turkey. Ankara, Siyasal Kitabevi, ISBN: 978-605-5782-62-7, 2011; 950-956.

Deryakulu D. Ve Kuzgun Y. "Bireysel Farklılıklar ve Eğitime Yansımaları” Eğitimde Bireysel Farklıliklar. Ankara, Nobel Yayıncilık, 2006.

Deveci T. İngilizce’yi Yabancı Bir Dil Olarak Öğrenen Yetişkinlerin Sosyal Etkileşime Dayalı Öğrenme Stilleri. Ankara Üniversitesi Eğitim Bilimleri Enstitüsü, Ankara, Doktora Tezi, 2011.

Diaz D.P. ve Ryan B.C. Students Learning Styles in Two Classes. Fall, College Teaching. 1999; 130.

Dikmen T.G. ve Saracaloğlu A.S. Öğretmen Adaylarının Öğrenme Stillerinin Çeşitli Değişkenler Açısından İncelenmesi. Adnan Menderes Üniversitesi Eğitim Bilimleri Dergisi, 2011; 52-74.

Dikmen Y. Kolb’un Öğrenme Stili Modeline Göre Hemşirelik Öğrencilerinin Öğrenme Stillerinin İncelenmesi. Journal of Human Rhythm, ISSN: 2149-455X, 2015; 101-106.

Duman B. Öğrenme-Öğretme Kuramları ve Süreç Temelli Öğretim. 1. Baskı, Ankara, Anı Yayınc1lik. 2004; 20-65.

Dunn R., Gianitti M.C., Murray J.B., Rossi I., Quinn GP. Two Sides of the Same Coin or Different Strokes for Different Folks. Teacher Librarian. 2001; 9.

Dobson J.L. A Comparison Between Learning Style Preferences and Sex, Status, and Course Performance. DOI: 10.1152/anvan.00078.2010, Physiology Education, 2010; 197-204.

Ekici G. Öğrenme Stiline Dayalı Çğretim ve Biyoloji Dersi Öğretimine Yönelik Ders Planı Örnekleri. 1. Bask1, Ankara, Gazi Kitabevi. 2003; 13-66.

Ekici G. Gregorc ve Kolb Öğrenme Stili Modellerine Göre Öğretmen Adaylarının Öğrenme Stillerinin Cinsiyet ve Genel Akademik Başarı Açısından İncelenmesi. Eğitim ve Bilim, Cilt:38, Say1:167, 2013; 211-225.

Ergür D.O. Hacettepe Üniversitesi Dört Ylllık Lisans Programlarındaki Öğrenci ve Öğretim Üyelerinin Öğrenme Stillerinin Karşılaştırılması. Hacettepe Üniversitesi Sosyal Bilimler Enstitüsü, Ankara, Doktora Tezi, 1998; 44.

Ersanlı K. ve Uzman E. Eğitim Psikolojisi. 1. Baskı, İstanbul, Lisans Yayıncılık. 2007; 303-385.

Felder R. Matters of Style. American Society for Engineering Education, USA: ASEE Prism, 1996; 5-23.

Fidan N. ve Erden M. Eğitime Giriş. Ankara, Meteksan. 1993.

Fidan N. Eğitim Psikolojisi, Okulda Öğrenme ve Öğretme. Ankara, Alkım Yayınevi. 1986.

Fidan N. Okulda Öğrenme ve Öğretme. Ankara, 1986; 196.

Filiz Büyükalan S. Öğrenme, Öğretme kuram ve Yaklaşımları. 1. Baskı, Ankara, pegem Akademi. 2011; 209-222.

Fleeming N. ve Baume D. Learning Styles Again : VARKing Up The Right Tree, Educational Developments. 2006; 4-7.

Gencel E.İ. Öğrenme Stilleri, Deneyimsel Öğrenme Kuramına Dayalı Eğitim, Tutum ve Sosyal Bilgiler Program Hedeflerine Eriş Düzeyi. Dokuz Eylül Üniversitesi Eğitim Bilimleri Enstitüsü, İzmir, Doktora Tezi, 2006; 112-113.

Gordon H.R.D. Identifiying Learning Styles. Paper Presented at the Annual Summer Workshop for Beginning Vocational Education Teachers. West Virginia, West Virginia University Institute of Technology, 1998; 247.

Griggs A.S. Learning Styles Counselling. ERIC: ED341890, 1990.

Günaydın F. İlköğretim 4. ve 5. Sınıf Öğrencilerinin Öğrenme Stilleri ile Ders Çalışma Alışkanlıkları Arasındaki İlişkinin İncelenmesş, Marmara Üniversitesi Eğitim Bilimleri Enstitüsü, İstanbul, Yüksek Lisans Tezi, 2011. 
Gürol M. Eğitim Teknolojisinde Yeni Paradigma : Oluşturmacıllk. Firat Üniversitesi Sosyal Bilimler Dergisi, Cilt:12, Sayı:1, DOI: 1012-0165, Elazığ. 2002;159-183.

Gürsoy T. Öğretmen Adaylarının Öğrenme Stillerinin Çeşitli Değişkenler Açısından İncelenmesi. Adnan Menderes Üniversitesi Sosyal Bilimler Enstitüsü, Aydın, Yüksek Lisans Tezi, 2008.

Güven M. Öğrenme Stilleri ile Öğrenme Stratejileri Arasındaki İlişki. Anadolu Üniversitesi Eğitim Bilimleri Enstitüsü, Eskişehir, Doktora Tezi, 2004.

Güven M. Öğrenme Stilleri ile Öğrenme Stratejileri Arasındaki İlişki. 1. Baskı, Eskişehir, T.C. Anadolu Üniversitesi Yayınları. 2004; 6-70.

GSU 2011. GSU Master Teacher Program : On Learning Styles. http://www2.gsu.edu/dschjb/ wwwmbti.html, 2017.

Holland, Christopher ve Mills, Claire D. Prolifing Sports Therapy students' Preferred Learning Styles Within A Clinical Education Context. University of Gloucestershire, Journal of Learning Development in Higher Education, ISSN: $\quad$ 1759-667X, 2015; 1-19.

Işıldar P., Aktaş E., Kurgun O.A. Turizm Öğrencilerinin VARK Öğrenme Modellerine Göre Öğrenme Stillerinin Belirlenmesi : Lisans ve Ön Lisans Karşılaştırması. Dokuz Eylül Üniversitesi Sosyal Bilimler Enstitüsü Dergisi, E-ISSN: 1308-0911. 2016; 91-113.

İlhan A. İngilizce Kurslarına Devam Eden Kursiyerlerin Öğrenme Stilleri. Hacettepe Üniversitesi Sosyal Bilimler Enstitüsü, Ankara, Yüksek Lisans Tezi, 2002.

Jonassen H.D. ve Barbara L.G. Handbook of Individual Differences, Learning and Instruction. USA, Lawrance Erlbaum Associates. 1999; 130.

Jonassen H.D. Thinking Technology : Toward A Constructivist Design Model. Educational Technology. 1994; 34-37.

Karasar N. Bilimsel Araştırma Yöntemleri (Scientific Research Methods). 12. Basım, Ankara, Nobel Yayıncllik. 2002; 77-79.

Katsioloudis P. ve D.Fantz T. A Comparative Analysis of Preferred Learning and Teaching Styles for Engineering, Industrial, and Technology Education Students and Faculty. Journal of Technology Education, Vol:23, No:2, 2012; 61-69.

Kayacık E. Öğrencilerin Kolb Öğrenme Stillerine Göre Çalışma Alışkanlıkları, Ödev Yapma Motivasyonları ve Stilleri Üzerine Bir Çalışma. Eskişehir Osmangazi Üniversitesi Eğitim Bilimleri Enstitüsü, Eskişehir, Yüksek Lisans Tezi, 2013.

Kocaarslan B. Profesyonel Müzik Eğitiminde Bilinçli Farkındalık, Öğrenme Stratejileri ve Öğrenme Stilleri. Marmara Üniversitesi Eğitim Bilimleri Enstitüsü, İstanbul, Doktora Tezi, 2016.

Koç D. Beden Eğitimi ve Spor Yüksekokulu Öğrencilerinin Öğrenme Stillerinin İncelenmesi ve Belirlenmesi. Marmara Üniversitesi Eğitim Bilimleri Enstitüsü, İstanbul, Yüksek Lisans Tezi, 2010.

Koç S. İlköğretim 5. ve 6. Sınıf Öğrencilerinin Öğrenme Stillerinin Belirlenmesi ve Akademik Başarı ile İlişkisi. Fırat Üniversitesi Sosyal Bilimler Enstitüsü, Elazı̆̆, Yüksek Lisans Tezi, 2009.

Koçyiğit M. Üniversite Öğrencilerinin Nedensel Yüklemeleri ve Öğrenme Stilleri. Afyon Kocatepe Üniversitesi Sosyal Bilimler Enstitüsü, Afyon, Yüksek Lisans Tezi, 2011.

Kolay B. Öğretim Stillerinin Farklı Öğrenme Stillerine Sahip 6. Sınıf Öğrencilerinin Fen ve Teknoloji Dersi Başarısı Arasındaki İlişki. Abant İzzet Baysal Üniversitesi Sosyal Bilimler Enstitüsü, Bolu, Yüksek Lisans Tezi, 2008.

Kolb A.Y. \& Kolb D.A. The Kolb Learning Style Inventory-Version 3.1. 2005 Thecnical Specification, Boston, MA: Hay Group Resources Direct, 2005.

Kolb D.A. Experiental Learning-Experience as The Source of Learning Development. New Jersey, Prentice Hall, 1984;81.

Kolb D.A. Learning -Style Inventory- Version 3. Boston, MA: Hay \& McBer Training Resources Group, 1999.

Köklü N. ve Büyüköztürk Ş. Sosyal Bilimler İçin İstatistiğe Giriş. Ankara, Pegem A Yayınları, 2000; 123. 


\section{8 | Spor Bilimlerinde Öğrenme ve Öğrenme Stilleri}

Köroğlu M. Öğretmen Adaylarının Özel Alan Yeterlikleri ile Öğrenme Stilleri Arasındaki İlişkinin İncelenmesi. Ahi Evran Üniversitesi Sosyal Bilimler Enstitüsü, Kırșehir, Yüksek Lisans Tezi, 2015.

Kul S. İstatistik Sonuçlarının Yorumu: P Değeri ve Güven Aralığı Nedir ? Türk Toraks Derneği, DOI: 10.5152/pb.2014.003, Gaziantep. 2014; 11-13.

Kurtman E. Öğrenme ve Öğretme Stilleri Arasındaki Uyumun Akademik Başarıya Etkisi. Bülent Ecevit Üniversitesi Sosyal Bilimler Enstitüsü, Zonguldak, Yüksek Lisans Tezi, 2013.

Lawrance W.K. The Experience of Contrasting Learning Styles, Learning Preferencesi and Personality Types in the Community College English Classroom. Northeastern University, Boston, Doctor of Education Thesis, 2013.

Leite W.L., Svinicki M. ve Shi Y. Attempted Validation of the Scores of the VARK : Learning Styles Inventory with Multitrait-Multimethod Confirmatory Factor Analysis Models. Educational and Psychological Mesaurement, 2010; 323-339.

Littlewood W.T. Foreign and Second language Learning. Language Acquisition Research and Its Implication fort he Classroom. USA, Cambridge, University Pres, 1984.

Lujan H.L. ve DiCarlo S.E. First-Year Medical Students Prefer Multiple Learning Styles. Department of Physiology. DOI: 10.1152/advan.00045.2005. 2006; 13-16.

Martin L.I. ve Clark L.F. Social Cognition Explorning The Mental Process Involved in Human Social Interaction. Cognitive Psychology: An International Review, England, Wiley. 1990; 548-562.

McCarthy B. The 4MAT System: Teaching to Learning Styles with Right/Left Mode Techniques. Barrington : Excel, 1987.

Miller P. Learning Styles and General Attitudes Toward Computers: An Analysis of Students Enrolled in Computer Science Modules at Calvin College. Research Field Study, IR: 020848, 2000.

Nuzhat A., Salem RO., Quadri MSA., Al-Hamdan N. Learning Style Preferences of Medical Students: A Single-Institute Experience from Saudi Arabia. International Journal of Medical Education, DOI: 10.5116/ijme.4e36.d31c, 2011; 70-73.

Orak Z. Türkiye’de Akademik Başarı Değişkeni Alanında Yapılan Öğrenme Stilleriyle İlgili Çalışmaların İncelenmesi. Mustafa Kemal Üniversitesi Sosyal Bilimler Enstitüsü, Hatay, Yüksek Lisans Tezi, 2015; 24-31.

Oral B. Öğrenme, Öğretme Kuram ve Yaklaşımları. 1. Baskı, Ankara, Pegem Akademi. 2011;257420.

Özbay Y. ve Erkan S. Eğitim Psikolojisi. 2. Baskı, Ankara, Pegem Akademi, 2009; 205-272.

Özdemir M. Sınıf Öğretmenliği Adaylarının Öğrenme Stillerinin Çeşitli Değișkenler Açısından İncelenmesi. Gazi Üniversitesi Eğitim Bilimleri Enstitüsü, Ankara, Doktora Tezi, 2011.

Özdemir N. ve Kesten A. Sosyal Bilgiler Öğretmenliği Adaylarının Öğrenme Stilleri ve Bazı Demografik Değişkenlerle İlişkisi. Atatürk Üniversitesi Sosyal Bilimler Enstitüsü Dergisi, Sayı:16, 2012; 361-377.

Özden Y. Öğrenme ve Öğretme. 7. Baskı, Ankara, Pegem A Yayıncllık. 2005; 21-46.

Özer B. Bilgi İşleme Kuramı / Gelişim ve Öğrenme. Eskişehir, Anadolu Üniversitesi Açıöğretim Fakültesi, 2001;157-176.

Özer B. Öğrenmeyi Öğretme / Eğitim Bilimlerinde Yenilikler. Eskişehir, Anadolu Üniversitesi Açıköğretim Fakültesi İlköğretim Öğretmenliği Lisans Tamamlama programı, 1998; 146-164.

Özgür H. Bilgisayar ve Öğretim Teknolojileri Eğitimi Bölümü Öğretmen Adaylarının Öğrenme Stillerinin Çeşitli Değişkenler Açısından İncelenmesi. Pamukkale Üniversitesi Eğitim Fakültesi Dergisi, Say1:34, 2013; 103-118.

Peker M. Kolb Öğrenme Stili Modeli. Milli Eğitim Dergisi, 2003.

Powers C.M. Music Student Satisfaction: The Relationship Between Learning Style Preferences and Major Satisfaction. University of Tennessee, Knoxville, Masters Thesis, 2016.

Reigeluth C. Instructional-Design Theories and Models. New Jersey, Lawrance Erlbaum Asspciates, Publishers, 1983. 
Riding R. ve Stephen R. Cognitive Styles and Learning Strategies-Understanding Style Differences in Learning and Behavior. London, David Fulton Publishers, 1998; 72.

Schunk D.H. Öğrenme Teorileri. Çev.: Muzaffer Şahin, Ankara, Nobel Yayıncılık, 2009.

Senemoğlu N. Gelişim, Öğrenme ve Öğretim Kuramdan Uygulamaya. 20. Baskı, Ankara, Pegem Akademi. 2011; 88-373.

Silberman M. Active Learning -101 Strategies- to Teach Any Subject. Boston, Allyn and Bacon, $1996 ; 4$

Silver H., Strong R. and Perini M. Integrating Learning Styles and Multiple Intelligences. Educational Leadership, 1997; 22-27.

Sönmez V. Öğretmenlik Mesleğine Giriş. Ankara, Anı Yayıncılık, 2004.

Stradley L.S., Bernadette D.B., Kaminski T.W., Horodyski M.B., Fleeming D., Christopher M.J. A Nationwide Learning Style Assesment of Undergraduate Athletic Training Students in CAAHEP-Accredited Athletic Training Programs. Journal of Athletic Training, 2002; 141-146.

Sümbüloğlu K. ve Sümbüloğlu V. Sağlık Bilimlerinde Araştırma Yöntemleri. 6. Baskı, Ankara, Hatipoğlu Yayınevi, 2013.

Süral S. Sınıf Öğretmenliği Öğretmen Adaylarının Öğrenme Stilleri ile Fen ve Teknoloji Öğretimi Dersindeki Akademik Başarıları Arasındaki İlişki. Pamukkale Üniversitesi Eğitim Bilimleri Enstitüsü, Denizli, Yüksek Lisans Tezi, 2008.

Tan Ş. Öğretim İlke ve Yöntemleri. 3. Baskı, Ankara, Pegem A Yayıncılık, 2008.

Temel A. "Öğrenme Stilinizi Belirleyin”. Eğitim ve Bilim, 2002; 6-9.

Tuna S. Resim-İ̧̀ Öğretmenliği Bölümü Öğrencilerinin Öğrenme Stilleri. Elektronik Sosyal Bilimler Dergisi, Cilt-Sayı: 7-25, ISSN: 1304-0278, 2008; 252-261.

Turan M.B. Beden Eğitimi ve Spor Öğretmenliği Bölümü’nde Öğrenim Gören Öğrencilerin Meraklılık Düzeyleri ile Öğrenme Stilleri Arasındaki İlişkinin İncelenmesi. Erciyes Üniversitesi Sağlık Bilimleri Enstitüsü, Kayseri, Yüksek Lisans Tezi, 2015; 4-62.

Ulusoy A. Gelişim ve Öğrenme. Ankara, Anı Yayıncılık, 2006.

Urval R.P., Kamath A., Ullal S., Shenoy A.K., Shenoy N., Udupa L.A. Assessment of Learning Styles of Undergraduate Medical Students Using the VARK Questionnaire and the Influence of Sex and Academic Performance. DOI: 10.1152/advan.00024.2014, 2014; 216-220.

Ülgen G. Eğitim Psikolojisi. İstanbul, Alkım Yayınevi, 1997; 35-38.

Ünal Ö. Pedagojik Formasyon Sertifika Programına Devam Eden Öğrencilerin Bireysel Öğrenme biçimlerinin Kolb’un Sınıflaması Temelinde İncelenmesi: Çukurova Üniversitesi Örneği. Çukurova Üniversitesi Sosyal Bilimler Enstitüsü, Adana, Yüksek Lisans Tezi, 2013.

Watkins, Chris, Carnell E., Lodge C., Wagner P., Whalley C. Learning About Learning. London, Routledge Falmer, 2000; 59-93.

Yağışan N. ve Sünbül A.M. Güzel Sanatlar Eğitimi Bölümü Öğrencilerinin Öğrenme Tercihleri. 8. Ulusal Müzik Eğitimi Sempozyumu, 23-25 Eylül, Ondokuz Mayıs Üniversitesi, Samsun, 2009; $1-13$.

Yılmaz D. Öğrenme Stratejilerinin öğrenme Stilleri ve Bazı Değişkenler Açısından İncelenmesi. Selçuk Üniversitesi Eğitim Bilimleri Enstitüsü, Konya, Yüksek Lisans Tezi, 2011.

Zahal O. Müzik Öğretmenliği Adaylarının Öğrenme Stilleri ve Alan Dersleri Başarıları Arasındaki İlişkiler. E-International Journal of Educational Research, DOI: 10.19160/e-ijer.57956, 2015; 46-70.

Zahal O. Özel Yetenek Sınavına Giren Adayların Öğrenme Stilleri ve Bilişsel Esneklik Düzeyleri ile Sınav Başarıları Arasındaki İlişki. İnönü Üniversitesi Eğitim Bilimleri Enstitüsü, Malatya, Doktora Tezi, 2014.

Zengin R. ve Alşahan LÖ. Öğretmen Adaylarının Öğrenme Stillerinin Bazı Değişkenler Açısından Değerlendirilmesi. NWSA-Education Sciences, ISSN: 1306-3111, Article Number: 1C0479, 2012; 133-139. 